\title{
Evaluation of ghrelin level and appetite regulation in patients with acute exacerbations of chronic obstructive pulmonary disease
}

This article was published in the following Dove Press journal:

International Journal of COPD

14 August 2014

Number of times this article has been viewed

\author{
Ye Wang ${ }^{1, \#}$ \\ Yongchun Shen ${ }^{1, \#}$ \\ Qiunan Zuo² \\ Li Zhao ${ }^{3}$ \\ Chun Wan' \\ Panwen Tian' \\ Lei Chen' \\ Fuqiang Wen'
}

'Department of Respiratory Medicine, West China Hospital of

Sichuan University and Division of Pulmonary Diseases, State Key Laboratory of Biotherapy of China, Chengdu, People's Republic of China; ${ }^{2}$ Department of Geriatrics, Sichuan Provincial People's Hospital, Chengdu, People's Republic of China; ${ }^{3}$ Department of Respiratory Medicine, Guizhou People's Hospital, Guizhou,

People's Republic of China

"These authors contributed equally to this work and share joint first authorship
Correspondence: Fuqiang Wen Department of Respiratory Medicine, West China Hospital of Sichuan University and Division of Pulmonary Diseases, State Key Laboratory of Biotherapy of China, Chengdu 61004I, People's Republic of China

Tel +8628 85422350

Fax +86 2885582944

Email wenfuqiang.scu@gmail.com
Background: Appetite reduction is a major cause of cachexia in acute exacerbations of chronic obstructive pulmonary disease (AECOPD). This study tested the correlation of appetite and circulating levels of acylated ghrelin in patients with AECOPD.

Methods: Thirty-six patients with AECOPD and 23 healthy adults were enrolled in this study. Circulating total ghrelin, acylated ghrelin, and obestatin levels, Simplified Nutritional Appetite Questionnaire (SNAQ) score, and caloric intake were compared in patients and healthy controls. Additionally, the above parameters were compared between admission and discharge in the patients with AECOPD.

Results: Compared with healthy controls, SNAQ scores and caloric intake were significantly lower in patients with AECOPD, but there were no significant differences in total ghrelin, acyl ghrelin, or obestatin levels. In patients with AECOPD, the total ghrelin level was significantly higher at admission than on discharge, the SNAQ score and caloric intake were significantly increased at discharge when compared with admission, and there was no significant difference in acylated ghrelin level between admission and discharge.

Conclusion: We demonstrated lower appetite scores and caloric intake in patients with AECOPD, but could not confirm that these effects were caused by insufficient levels of the orexigenic peptide, acyl ghrelin. Further studies are needed to confirm our findings and to determine the mechanism regulating appetite in patients with AECOPD.

Keywords: ghrelin, appetite, pulmonary disease, chronic obstructive, malnutrition, comorbidities

\section{Introduction}

Malnutrition is one of the most common comorbidities in patients with chronic obstructive pulmonary disease (COPD), and is also an independent risk factor for death in these patients. ${ }^{1,2}$ In addition to excessive energy expenditure on exertive breath and the inflammatory response, ${ }^{3}$ patients with COPD, especially those with acute exacerbations, usually have a worse appetite and ingest less food. Appetite is known to be regulated by a fine balance between orexigenic and anorexigenic neuropeptides in the hypothalamus. Among these peptides, neuropeptide $Y$ and agouti-related peptide are potent orexigenic peptides, and are released by neuropeptide Y/agouti-related peptide neurons. ${ }^{4}$ On the surface of these neurons, abundant G-protein coupled receptors, so-called growth hormone secretagogue receptors, are present to mediate growth hormone secretion in the pituitary gland. ${ }^{5}$

Ghrelin is an endogenous ligand of the growth hormone secretagogue receptor, secreted primarily in the stomach and secondarily in the other portions of the 
digestive tract. ${ }^{6}$ Ghrelin and another 23 -amino acid peptide, obestatin, are derived from the 99-amino acid precursor, proghrelin. ${ }^{7}$ The active form of ghrelin has a unique modification of an octancyl group on Ser3, and accounts for 10\%-40\% of total ghrelin. ${ }^{8-11}$ The acylation modification provides large hydrophobic groups, which are essential for activation of the growth hormone secretagogue receptor. The wide distribution of growth hormone secretagogue receptors suggests a variety of physiological roles for acylated (acyl) ghrelin, including stimulation of appetite, regulation of glucose metabolism, and long-term regulation of energy balance. ${ }^{12}$ These functions are regulated by circulating levels of acyl ghrelin.

Itoh et al first studied ghrelin in COPD because of the close association between ghrelin and nutritional status, and reported an elevated plasma ghrelin level in underweight patients. ${ }^{13}$ Thereafter, several studies compared the plasma ghrelin level in stable COPD patients and healthy controls, but inconsistent results were reported. ${ }^{14-17}$ These works focused on the association of ghrelin level with body mass index, inflammatory markers, and other related peptides, but none measured acyl ghrelin level or assessed appetite. Although Nagaya et al showed that ghrelin effectively treated underweight COPD patients, ${ }^{18}$ whether the reduction of appetite was associated with a lower plasma ghrelin level in COPD is unclear.

A very poor appetite is observed in many patients with acute exacerbation of chronic obstructive pulmonary disease (AECOPD), and these patients usually have complications of gastric mucosal injury and gastrointestinal disorders, particularly those with a severe inflammatory response, hypoxia, or hypercapnia. Until now, limited studies have examined circulating levels of acyl ghrelin in patients with AECOPD. This study aimed to measure circulating levels of total and acyl ghrelin in AECOPD, and evaluated patients' appetite and caloric intake, in order to explore the possible relationship between ghrelin secretion, acylation, and appetite regulation in patients with AECOPD.

\section{Materials and methods}

This study was approved by the institutional review board of Sichuan University (approval number ChiCTR-OCS12001888). Informed consent was obtained from all subjects.

\section{Study subjects}

Thirty-six consecutive patients with AECOPD admitted to West China Hospital, Sichuan University, Chengdu, People's Republic of China, were enrolled in this study. COPD and
AECOPD were diagnosed based on 2013 GOLD (Global Initiative for Chronic Obstructive Lung Disease) criteria. Patients with diabetes, hypertension, gastritis, or pulmonary encephalopathy were excluded due to possible interference with appetite assessment and ghrelin measurement. An age-matched subset of 23 healthy adults was recruited as the control.

All the patients were previously diagnosed with COPD in outpatient care or during a previous hospitalization, and had recent pulmonary function test results (within 6 months). Forced vital capacity and forced expiratory volume in one second $\left(\mathrm{FEV}_{1}\right)$ were measured by standard spirometric techniques (MasterScreen ${ }^{\mathrm{TM}}$ spirometer; CareFusion Germany 234 GmbH, Höchberg, Germany), using the reference values proposed by Zheng and Zhong. ${ }^{19}$ GOLD stage was determined by the patient's lung function data. The height and weight of each patient was measured at discharge to avoid deviations in the status of acute exacerbation.

\section{Study design}

Total ghrelin, acyl ghrelin, and obestatin levels were recorded, along with evaluation of appetite and caloric intake, at both admission and discharge in the patients with AECOPD. The Simplified Nutritional Appetite Questionnaire (SNAQ) ${ }^{20}$ was used to evaluate appetite in all subjects, and caloric intake was measured with reference to the China Food Composition for the calorie count of each type of food. ${ }^{21}$ These parameters were also compared between healthy controls and patients with AECOPD at admission.

For each patient with AECOPD, two blood samples were taken, one in the first 24 hours after admission to hospital and the other on the day before discharge. Blood was taken from the antecubital vein at around 7 am after an overnight fast. Administration of glucocorticoids, glucose, and intravenous nutrition was avoided in the 24 hours before blood sampling. The samples were processed as quickly as possible to avoid breakdown of peptides, and then centrifuged at $4^{\circ} \mathrm{C}$ and stored at $-80^{\circ} \mathrm{C}$ until analysis. Plasma levels of total ghrelin, acylated ghrelin, and obestatin were measured using radioimmunoassay kits (Millipore, Billerica, MA, USA) following the manufacturer's instructions. Peptide measurements and appetite assessments were not performed in 13 patients with AECOPD at discharge (two who died, four who were intubated, and seven who were discharged ahead of time). C-reactive protein and interleukin- 6 were measured by the Department of Laboratory Medicine, West China 
Hospital, with immunoturbidimetric assays at admission and at discharge. These measurements were also performed in controls.

\section{Statistical analysis}

The data were expressed as the mean \pm standard deviation (normal distribution) or the median (interquartile range; skewed distribution). The parameters were compared between the acute exacerbation and the remission phase of COPD using the paired Student's $t$-test (for differences with normal distribution) or the Wilcoxon signed-rank test (for differences with skewed distribution). Comparisons of parameters between patients and controls were made using the two independent samples Student's $t$-test or the Wilcoxon rank-sum test. Correlations between plasma ghrelin and pulmonary function parameters were examined by Pearson correlation or Spearman correlation analysis. $P<0.05$ was considered to be statistically significant.

Table I Patient characteristics

\begin{tabular}{|c|c|c|}
\hline & Controls $(n=23)$ & $\begin{array}{l}\text { AECOPD } \\
(n=36)\end{array}$ \\
\hline Age, years & $66.9 \pm 6.7$ & $65.6 \pm 7.6^{\mathrm{a}}$ \\
\hline Sex, male/female & $15 / 8$ & $27 / 9$ \\
\hline Body mass index, $\mathrm{kg} / \mathrm{m}^{2}$ & $22.39 \pm 3.51$ & $20.5 \pm 2.98^{\dagger}$ \\
\hline \multicolumn{3}{|l|}{ Smoking history } \\
\hline Nonsmokers, n & 7 & 14 \\
\hline Smokers, n (pack years) & $16(30.5 \pm 26.8)$ & $22(39.03 \pm 30.4)^{\mathrm{a}}$ \\
\hline \multicolumn{3}{|l|}{ Pulmonary function } \\
\hline $\mathrm{FEV}_{1}, \mathrm{~L}$ & $1.59 \pm 0.84^{\mathrm{a}}$ & $0.86 \pm 0.40^{*, a}$ \\
\hline $\mathrm{FEV}_{1}, \%$ Ref & $91.79 \pm 12.53$ & $35.39 \pm 13.64^{*, a}$ \\
\hline $\mathrm{FEV}_{1} / \mathrm{FVC}, \%$ & $75.62 \pm 3.81$ & $40.04 \pm 8.3 I^{*}$ \\
\hline FVC, L & $2.92 \pm 0.65$ & $2.11 \pm 0.7 I *$ \\
\hline FVC, \%Ref & $91.85 \pm 12.24$ & $67.41 \pm 20.92 *$ \\
\hline Length of remission, days & & $11.7 \pm 3.52$ \\
\hline Duration of disease, years & & $14.2 \pm 6.78$ \\
\hline \multicolumn{3}{|l|}{ Severity stage, n } \\
\hline I & & NA \\
\hline II & & 4 \\
\hline III & & 16 \\
\hline IV & & 16 \\
\hline \multicolumn{3}{|l|}{ Medication use, $\mathrm{n}$} \\
\hline Antibiotics & & 36 \\
\hline \multicolumn{3}{|l|}{ Intravenous } \\
\hline glucocorticoids & & 12 \\
\hline \multicolumn{3}{|l|}{ Inhaled glucocorticoids } \\
\hline and $\beta$-agonist & & 34 \\
\hline Anticholinergics & & 14 \\
\hline \multicolumn{3}{|l|}{ With pulmonary heart } \\
\hline disease, $\mathrm{n}$ & & 17 \\
\hline
\end{tabular}

Notes: a Data with skewed distribution were expressed as medians [IQR]; ${ }^{*} \mathrm{P}<0.00 \mathrm{I}$; $+P=0.021$.

Abbreviations: AECOPD, acute exacerbation of chronic obstructive pulmonary disease; FVC, forced vital capacity; FEV , forced expiratory volume in one second; $I Q R$, interquartile range; Ref, reference value; NA, not applicable.

\section{Results \\ Patient characteristics}

As shown in Table 1, there were 27 males and nine females in the AECOPD group, and 15 males and eight females in the control group. No significant differences in age or sex were observed between patients and controls at admission. The body mass index of the patients was significantly less than that of controls. Sixteen healthy controls and 22 patients with AECOPD were smokers, and there was no significant difference in pulmonary function $\left(\mathrm{FEV}_{1} \%\right.$, forced vital capacity), C-reactive protein, interleukin-6, pressure of oxygen $\left(\mathrm{pO}_{2}\right)$ or pressure of carbon dioxide $\left(\mathrm{pCO}_{2}\right)$ between smokers and nonsmokers with AECOPD. Pulmonary function tests were significantly worse in patients with AECOPD than in healthy controls, with much lower $\mathrm{FEV}_{1}$ (and $\mathrm{FEV}_{1} \%$ ) values. The numbers of patients in each COPD stage were GOLD $1(n=0)$, GOLD 2 ( $\mathrm{n}=4)$, GOLD 3 ( $\mathrm{n}=16)$, and GOLD 4 (n=16).

The mean duration of COPD was 14.2 years. All patients had received antibiotic therapies. Thirty-four patients had been treated with inhaled glucocorticoids, 12 with intravenous glucocorticoids, and 14 with inhaled anticholinergics. The mean length of stay in hospital was 11.7 days. Seventeen patients also had pulmonary heart disease, diagnosed accord-

Table 2 Results of blood analysis and biochemical indices

\begin{tabular}{|c|c|c|c|}
\hline & \multirow{2}{*}{$\begin{array}{l}\text { Controls } \\
(n=23)\end{array}$} & \multicolumn{2}{|l|}{ AECOPD } \\
\hline & & $\begin{array}{l}\text { Admission } \\
(n=36)\end{array}$ & $\begin{array}{l}\text { Discharge } \\
(n=23)\end{array}$ \\
\hline \multicolumn{4}{|l|}{ Blood gas analysis } \\
\hline $\mathrm{pO}_{2}, \mathrm{mmHg}$ & $79.9 \pm 6.2$ & $74.5 \pm 19.3$ & $75.45 \pm I I .0$ \\
\hline $\mathrm{pCO}_{2}, \mathrm{mmHg}$ & $39.1 \pm 1.4$ & $55.2 \pm 9.8^{*, a}$ & $48.8 \pm 7.3$ \\
\hline $\mathrm{pH}$ & $7.39 \pm 0.02$ & $7.39 \pm 0.05$ & $7.40 \pm 0.03$ \\
\hline $\mathrm{HCO}_{3}, \mathrm{mmol} / \mathrm{L}$ & $24.5 \pm 1.2$ & $32.4 \pm 4.3^{*}$ & $30.5 \pm 4.1$ \\
\hline \multicolumn{4}{|l|}{ Biochemistry } \\
\hline Protein, g/L & $72.1 \pm 3.37^{\mathrm{a}}$ & $64.4 \pm 8.08^{*, \mathrm{a}}$ & $60.3 \pm 6.58$ \\
\hline Albumin, $g / L$ & $45.6 \pm 3.37$ & $37.6 \pm 3.95^{*}$ & $35.3 \pm 4.47$ \\
\hline Cholesterol, $\mathrm{mmol} / \mathrm{L}$ & $4.0 \pm 0.34$ & $4.0 \pm 0.76$ & $3.8 \pm 0.81$ \\
\hline Glucose, $\mathrm{mmol} / \mathrm{L}$ & $5.2 \pm 0.50$ & $5.6 \pm 0.86^{\dagger}$ & $5.6 \pm 0.80$ \\
\hline Potassium, $\mathrm{mmol} / \mathrm{L}$ & $4.1 \pm 0.18$ & $4.08 \pm 0.4 I$ & $4.0 \pm 0.43$ \\
\hline Sodium, mmol/L & $|38.3 \pm 1.8|$ & $|4| .6 \pm 4.76 *$ & $142.1 \pm 5.5$ \\
\hline \multicolumn{4}{|l|}{ Routine analysis of blood } \\
\hline Hemoglobin, g/L & $139.8 \pm 12.2$ & $129.6 \pm 14.3^{\ddagger}$ & $130.6 \pm 16.3$ \\
\hline$W B C \times 10^{9} / \mathrm{L}$ & $6.03 \pm 1.41$ & $8.23 \pm 3.31^{*, a}$ & $7.56 \pm 2.14$ \\
\hline Neutrophils, \% & $50.7 \pm 17.0^{\mathrm{a}}$ & $76.5 \pm 9.52 *$ & $72.0 \pm 6.41$ \\
\hline \multicolumn{4}{|l|}{ Inflammatory markers } \\
\hline $\mathrm{CRP}, \mathrm{mg} / \mathrm{L}$ & $6.0 \pm 2.71$ & $33.5 \pm 9.54^{*, \mathrm{a}}$ & $22.4 \pm 17.3^{\mathrm{a}}$ \\
\hline IL-6, pg/mL & $5.4 \pm 2.73$ & $14.6 \pm 7.2^{*, a}$ & $14.8 \pm 9.6^{a}$ \\
\hline
\end{tabular}

Notes: a ${ }^{D}$ ata with skewed distribution were expressed as medians [IQR]. $* P<0.001$, $\uparrow P=0.023, \neq P=0.00$ for $A E C O P D$ versus controls.

Abbreviations: AECOPD, acute exacerbation of chronic obstructive pulmonary disease; CRP, C-reactive protein; WBC, white blood cells; IL-6, interleukin 6; $\mathrm{pO}_{2}$, pressure of oxygen; $\mathrm{PCO}_{2}$, pressure of carbon dioxide. 
ing to evidence of pulmonary hypertension, right heart insufficiency, and/or enlargement of the right heart ventricle.

\section{Circulating levels of blood cells and biochemical indices}

Blood cell counts, biochemical indices, and inflammatory markers for all subjects are shown in Table 2. Compared with healthy controls, patients with AECOPD at the peak of their exacerbation (on admission) had significantly higher white blood cell counts, percentage of neutrophils, $\mathrm{pCO}_{2}, \mathrm{HCO}_{3}$, C-reactive protein, interleukin-6, and glucose levels, and significantly lower hemoglobin, protein, and albumin levels. Twenty-eight patients with AECOPD received low-flow oxygen therapy, so the difference in $\mathrm{pO}_{2}$ between patients and controls was not statistically significant.

In the 23 patients with AECOPD who underwent two blood sampling collections, there was no significant difference in blood cell count, $\mathrm{pO}_{2}$ level, or $\mathrm{pH}$ value between the two measurement points (at admission and discharge). When compared with values at admission, $\mathrm{pCO}_{2}$, protein, albumin, C-reactive protein, and interleukin-6 levels were significantly lower at discharge.

\section{Evaluation of appetite and caloric intake}

Appetite, evaluated by SNAQ score, was significantly worse in patients with AECOPD at admission than in healthy controls. Patients with AECOPD at the peak of their exacerbation had a much lower daily calorie intake than healthy controls (Figure 1). After treatment, SNAQ scores and calorie intake in patients with AECOPD were both increased at discharge (Figure 2).

\section{Circulating levels of ghrelin and related peptides}

On admission, circulating levels of acyl ghrelin were not significantly different between patients with AECOPD and

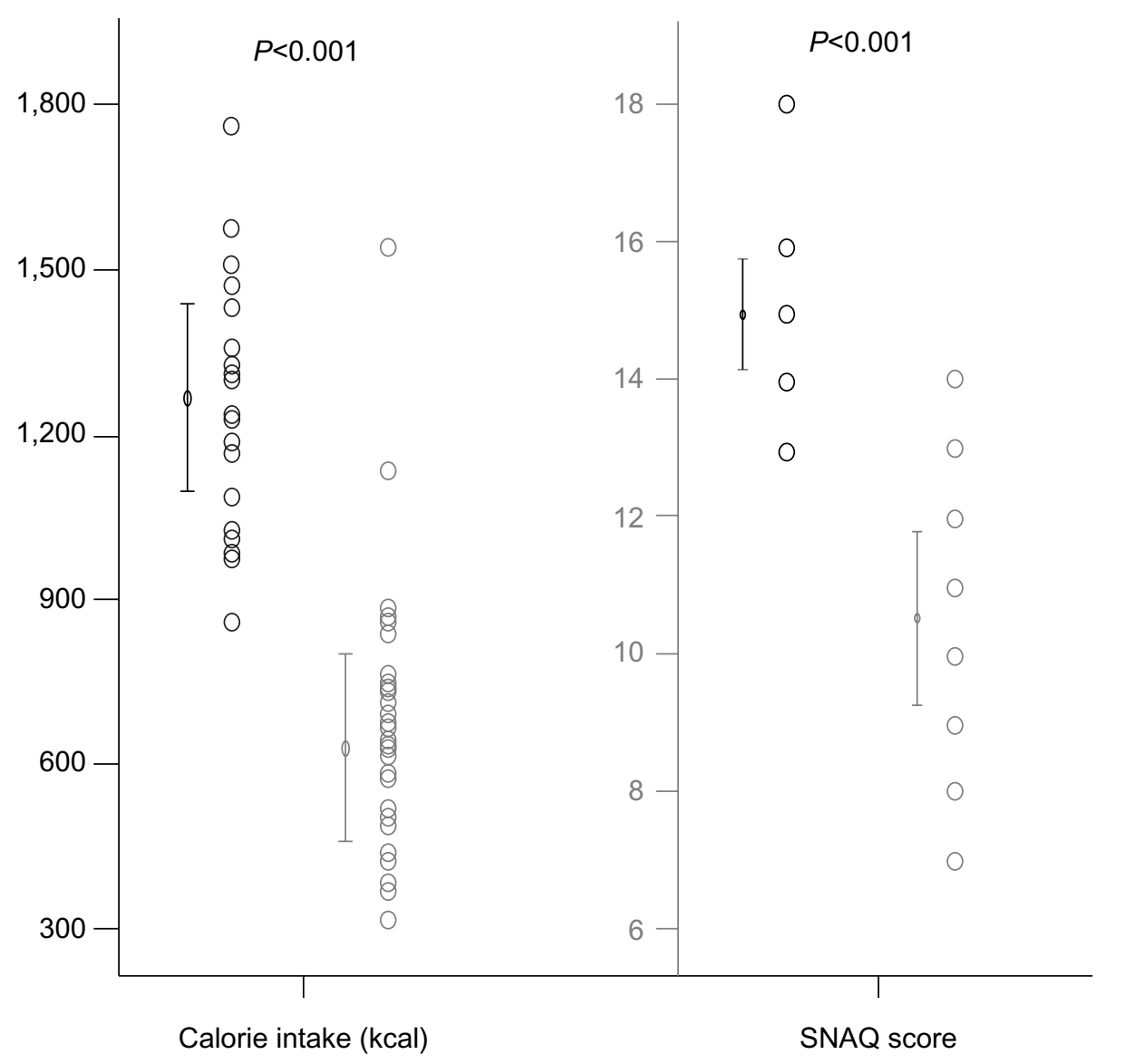

Figure I Caloric intake and SNAQ score in patients with AECOPD and healthy controls.

Notes: The SNAQ score was significantly lower in patients with AECOPD than in healthy controls $(P<0.00 \mathrm{I})$. Patients with AECOPD had a lower calorie intake in I day than healthy controls $(P<0.00 \mathrm{I}, 95 \%$ confidence interval $-721.8,-499.3)$.

Abbreviations: AECOPD, acute exacerbation of chronic obstructive pulmonary disease; SNAQ, Simplified Nutritional Appetite Questionnaire. 
$\mathrm{n}=23 \quad \circ$ At admission $\circ$ At discharge

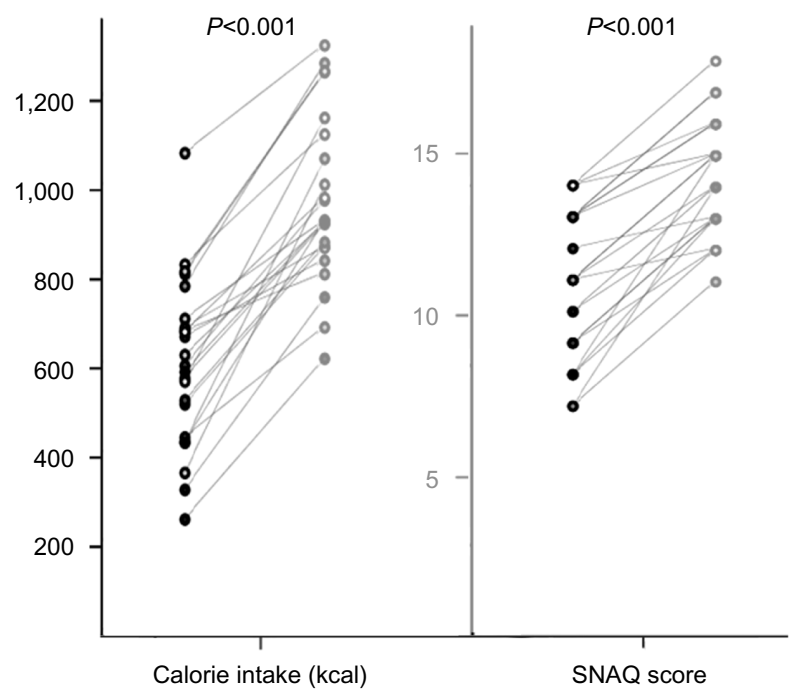

Figure 2 Caloric intake and SNAQ score in patients with AECOPD at admission and on discharge.

Notes: Patients with AECOPD at admission had significantly lower SNAQ scores $(P<0.00 \mathrm{I}, 95 \%$ confidence interval $-4.2,-2.8)$ and had a lower calorie intake $(P<0.00 \mathrm{I}$, $95 \%$ confidence interval $-429.8,-306.1)$ than when evaluated at discharge.

Abbreviations: AECOPD, acute exacerbation of chronic obstructive pulmonary disease; SNAQ, Simplified Nutritional Appetite Questionnaire. healthy controls, and there were no significant differences in total ghrelin or obestatin levels. However, the acyl to total ghrelin ratio was significantly lower in patients with AECOPD when compared with healthy controls (Figure 3 ).

Patients at the peak of exacerbation (on admission) had significantly higher circulating total ghrelin levels than at discharge. Obestatin levels were also higher at admission. There was no significant difference in the acyl to total ghrelin ratio between admission and discharge (Figure 4).

In patients with AECOPD, the ghrelin level at admission was negatively correlated with $\mathrm{FEV}_{1} \%(r=-0.537$, $P=0.008)$. Correlations between total ghrelin level and body mass index as well as inflammatory cytokines were not significant. In addition, there was no significant difference in circulating levels of ghrelin or other related peptides between smokers and nonsmokers, or between patients with and without respiratory failure. Notably, the difference in albumin level between patients at discharge and on admission was positively correlated with the total ghrelin level (Figure 5).

○ Controls $(n=23) \quad \circ$ Patients $(n=36)$

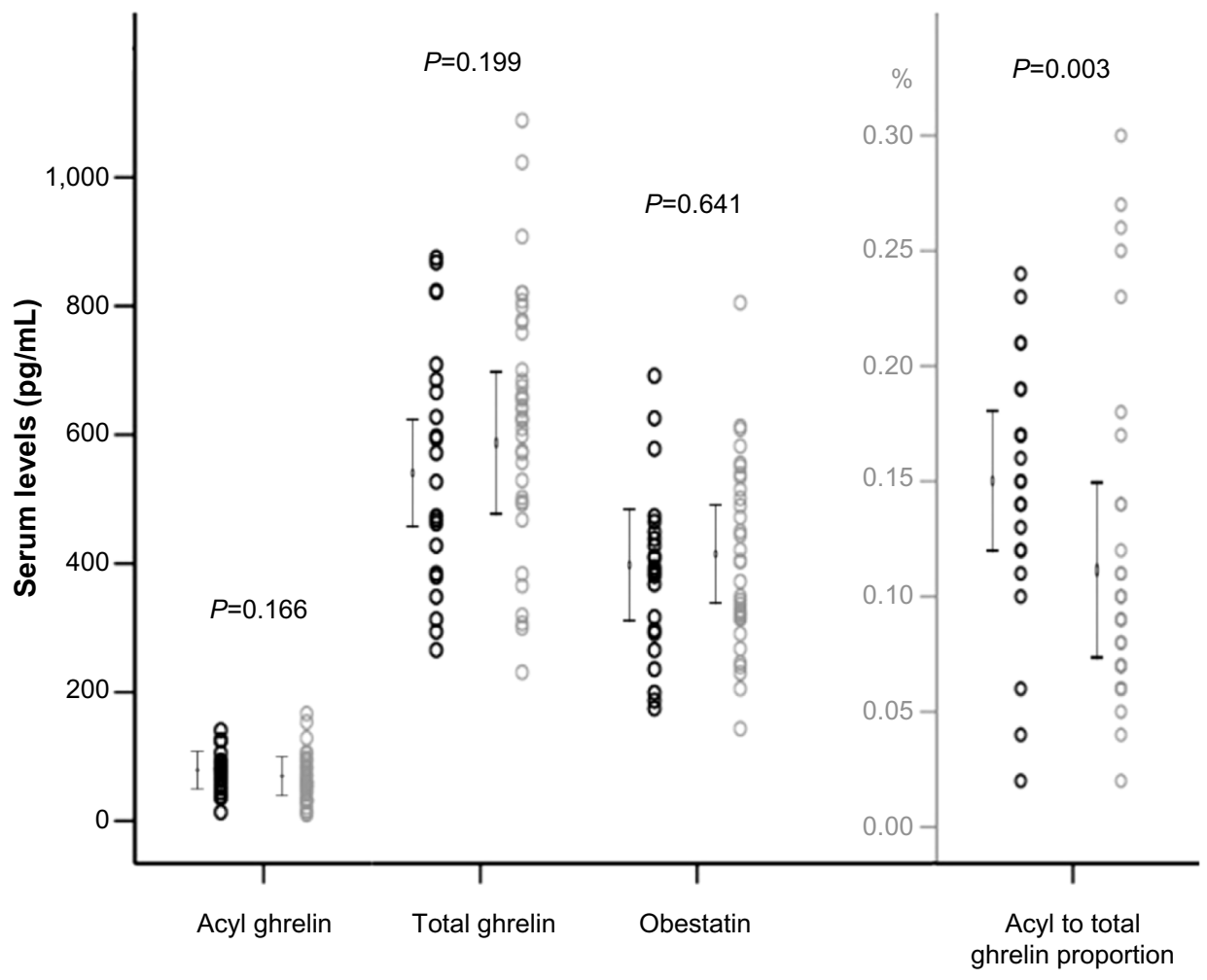

Figure 3 Acyl ghrelin, total ghrelin, obestatin, and acyl to total ghrelin ratios in patients with AECOPD and healthy controls.

Notes: The circulating level of acyl ghrelin was not significantly different between patients with AECOPD and healthy controls $(66.8 \mathrm{I} \pm 42.88 \mathrm{pg} / \mathrm{mL}$ versus $8 \mathrm{I} .30 \pm 33.3 \mathrm{I} \mathrm{pg} / \mathrm{mL}$, $P=0.327,95 \%$ confidence interval $-30.7,10.4)$. In addition, there was no significant difference in levels of total ghrelin $(623.6 \mathrm{I} \pm 196.24 \mathrm{pg} / \mathrm{mL}$ versus $556.83 \pm 186.2 \mathrm{I} \mathrm{Pg} / \mathrm{mL}$, $P=0.199,95 \%$ confidence interval -36.1 , I69.6) or obestatin $(402.04 \pm 139.94 \mathrm{pg} / \mathrm{mL}$ versus $384.88 \pm 133.04 \mathrm{pg} / \mathrm{mL}, P=0.478)$. The acyl to total ghrelin ratio was significantly lower in patients with $A E C O P D$ than in healthy controls $(P=0.003)$.

Abbreviation: AECOPD, acute exacerbation of chronic obstructive pulmonary disease. 


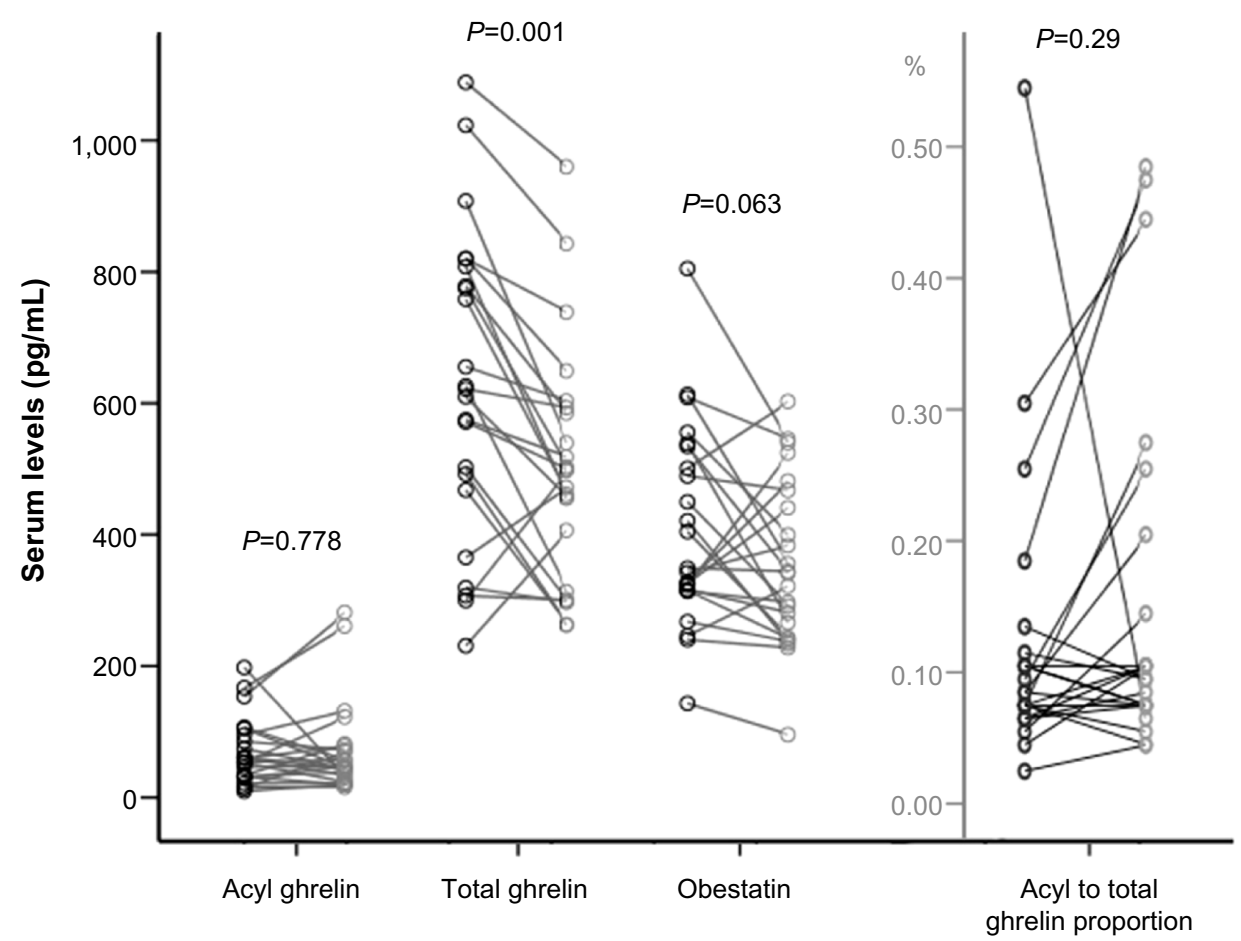

Figure 4 Acyl ghrelin, total ghrelin, obestatin, and acyl to total ghrelin ratio in patients with AECOPD at admission and on discharge.

Notes: Patients with AECOPD had a significantly higher circulating level of total ghrelin at admission than on discharge $(627.20 \pm 234.86 \mathrm{pg} / \mathrm{mL}$ versus $500.82 \pm 181.01 \mathrm{pg} /$ $\mathrm{mL}, P=0.00 \mathrm{I}, 95 \% \mathrm{Cl} 59.3,193.4)$. The obestatin level was higher at admission than on discharge $(410.05 \pm 152.35 \mathrm{pg} / \mathrm{mL}$ versus $354.94 \pm 127.80 \mathrm{pg} / \mathrm{mL}, P=0.063,95 \% \mathrm{Cl}-3.2$, | 13.4). In addition, there were no significant differences in the acyl ghrelin level $(67.77 \pm 50.29 \mathrm{pg} / \mathrm{mL}$ versus $71.24 \pm 70.05 \mathrm{pg} / \mathrm{mL}, P=0.778,95 \% \mathrm{Cl}-21.8,28.7)$ or acyl to total ghrelin ratio $(P=0.290,95 \% \mathrm{Cl}-0.03,0.30)$.

Abbreviations: AECOPD, acute exacerbation of chronic obstructive pulmonary disease; $\mathrm{Cl}$, confidence interval.

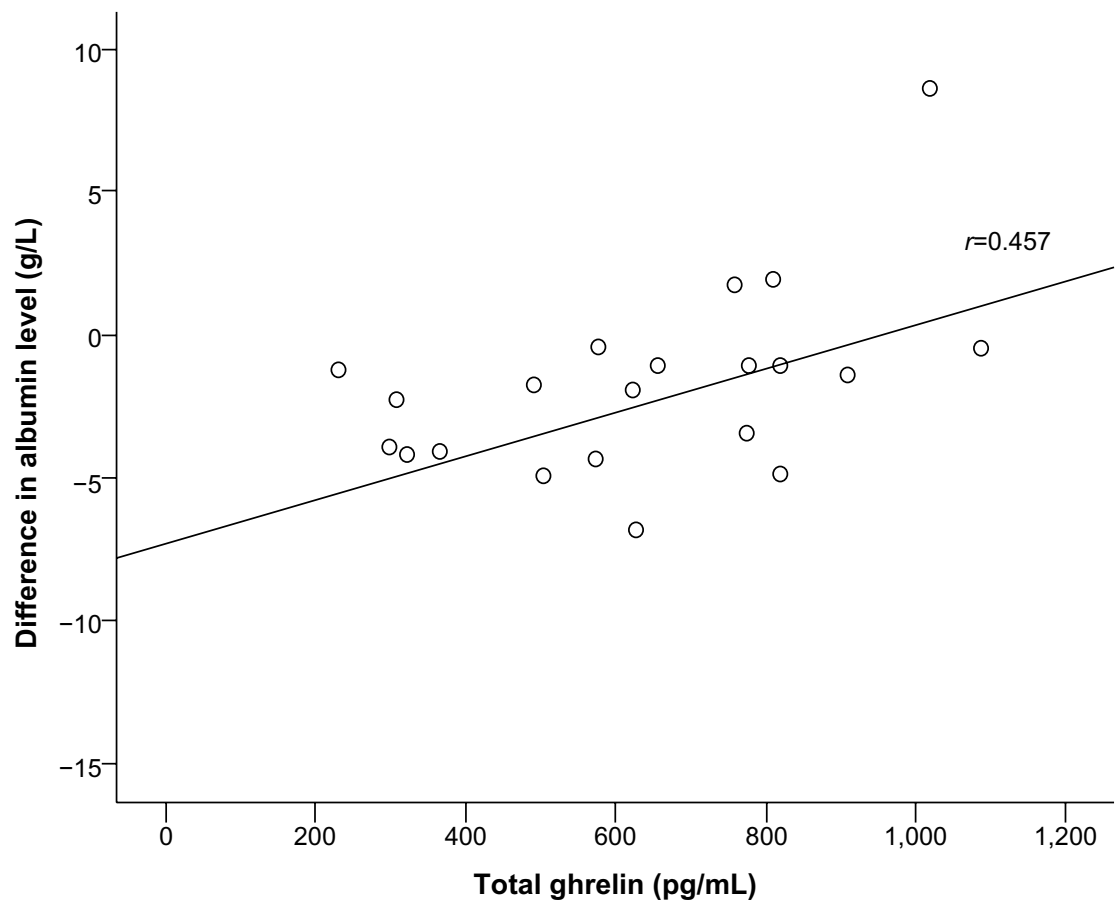

Figure 5 Difference in albumin level in patients with AECOPD at admission and on discharge versus total ghrelin level.

Note: The difference in albumin level in patients with an AECOPD at discharge and on admission was positively correlated with total ghrelin level ( $r=0.457, P=0.028)$.

Abbreviation: AECOPD, acute exacerbation of chronic obstructive pulmonary disease. 


\section{Discussion}

In the present study, we demonstrated that patients with AECOPD had a significantly worse appetite, a lower calorie intake, and a lower acyl to total ghrelin ratio than controls, but the differences in acyl ghrelin and total ghrelin levels were not statistically significant. In addition, we found that SNAQ scores and caloric intake in patients with AECOPD were significantly increased, while the total ghrelin level was decreased at discharge after treatment. There was no significant difference in the acyl ghrelin to total ghrelin ratio between admission and discharge. Further, we found that the circulating level of ghrelin at admission was positively correlated with the differences in albumin levels during hospitalization, but was negatively correlated with $\mathrm{FEV}_{1}$.

To test our hypothesis that decreased appetite in AECOPD is caused by a lower circulating level of acyl ghrelin, we compared patients with AECOPD and healthy controls. The appetite score and caloric intake were both significantly lower in patients with AECOPD than in healthy controls, but we did not find a significantly lower circulating level of acyl ghrelin in these patients. Moreover, we observed a significantly smaller appetite in patients at the peak of their exacerbation, but the change in acyl ghrelin level was not consistent with change in appetite in most patients. Therefore, we cannot conclude that the decreased appetite is caused mainly by a lower acyl ghrelin level.

Compared with healthy controls, the difference in total ghrelin level was not significant in patients with AECOPD at admission. This finding may be due to the small sample size in our study. Another explanation is that many factors can inhibit the secretion of ghrelin. For example, patients with a severe inflammatory response, hypoxia, or hypercapnia usually have complications of gastric mucosal injury and gastrointestinal disorders, so secretion and acylation of ghrelin in the stomach is vulnerable in AECOPD. On the other hand, catabolism and low caloric intake in patients with AECOPD could upregulate the secretion of ghrelin as a compensation mechanism. ${ }^{22}$ All these factors affect the circulating ghrelin level. However, for patients with AECOPD, the total ghrelin level at the peak of exacerbation was significantly higher than that at discharge, indicating that the compensation mechanism is a more dominant factor in stimulating ghrelin secretion.

The ratio of acyl ghrelin to total ghrelin was significantly lower in patients with AECOPD at admission than in healthy controls. This finding suggests that the acylation ratio of ghrelin in patients with AECOPD was probably less than the normal value. As explained above, production of acyl ghrelin, including secretion and acylation, occurs primarily in the stomach. Because mucosal injury and impaired stomach function are common complications in AECOPD, especially in those with a severe systemic inflammatory response and respiratory failure, the activity of ghrelin-Oacyltransferase, ${ }^{23}$ an enzyme that catalyzes ghrelin acylation, is probably less than that under normal conditions. Measuring the acyl ghrelin level and the activity of ghrelin$\mathrm{O}$-acyltransferase by endoscopic biopsy is a more direct and accurate method, but patients rarely consented to gastroscopy during an exacerbation. Another possible reason for a lower acyl to total ghrelin ratio in patients with AECOPD is that the breakdown of acyl ghrelin might be more rapid in the inflammation exacerbations, but further studies are needed to provide more evidence of this.

The appetite is regulated not only by orexigenic peptides, such as ghrelin, but also by anorexigenic peptides, such as lysates of pro-opiomelanocortin precursor protein, ie, melanocyte-stimulating hormone. The melanocortin system is a key site for the action of ghrelin, where agouti-related peptide competitively inhibits activation of melanocyte-stimulating hormone on downstream neurons that express melanocortin- 4 receptors. It has been reported that the systemic inflammatory response increases the activity of neurons expressing pro-opiomelanocortin and release of melanocyte-stimulating hormone, resulting in decreased appetite and increased degradation of nutrients or tissue. Based on the currently available evidence, the correlations of ghrelin and acetylated ghrelin with the food questionnaire scores and caloric intake remain unclear; and regulation of appetite probably depends on a fine balance of orexigenic and anorexigenic neuropeptides in the hypothalamus. Further studies are needed to investigate this.

In this study, we found that the circulating level of albumin was decreased after treatment in patients with AECOPD. Interestingly, the circulating level of ghrelin was positively correlated with that of albumin, suggesting the possible positive regulation of ghrelin on nitrogen balance. A recent study has reported the role of des-acyl ghrelin in glucose metabolism and adiposity. ${ }^{24}$ Miki et al reported that ghrelin intervention achieved improvements in symptoms and ventilatory/cardiac parameters in cachectic patients with COPD, suggesting a potential role of ghrelin in the treatment of COPD. ${ }^{25}$ However, further studies are required to investigate whether acyl ghrelin or des-acyl ghrelin participates in protein metabolism and is of benefit in patients. 


\section{Conclusion}

In summary, we demonstrated lower appetite scores and caloric intake in patients with AECOPD, but could not confirm that these effects were caused by insufficient levels of the orexigenic peptide, acyl ghrelin. The reasons for the appetite reduction and the factors associated with acyl ghrelin are multifactorial. Larger, more detailed studies are needed to confirm our findings and determine the mechanism regulating appetite in patients with AECOPD.

\section{Acknowledgments}

This study was supported in part by grants (81300032, 31171103 , and 81230001) from the National Natural Science Foundation of China, and a grant (2013SZ0001) from the Projects in the Science and Technology Pillar Program, Department of Science and Technology of Sichuan Province. The authors would like to thank Deying Kang and Shihong Zhou (West China School of Public Health, Sichuan University, Chengdu, People's Republic of China) for help with the statistical analysis.

\section{Disclosure}

The authors report no conflicts of interest in this work.

\section{References}

1. Obase Y, Mouri K, Shimizu H, et al. Nutritional deficits in elderly smokers with respiratory symptoms that do not fulfill the criteria for COPD. Int J Chron Obstruct Pulmon Dis. 2011;6:679-683.

2. Hallin R, Gudmundsson G, Suppli Ulrik C, et al. Nutritional status and long-term mortality in hospitalised patients with chronic obstructive pulmonary disease (COPD). Respir Med. 2007;101:1954-1960.

3. Sergi G, Coin A, Marin S, et al. Body composition and resting energy expenditure in elderly male patients with chronic obstructive pulmonary disease. Respir Med. 2006;100:1918-1924.

4. Kamegai J, Tamura H, Shimizu T, Ishii S, Sugihara H, Wakabayashi I. Chronic central infusion of ghrelin increases hypothalamic neuropeptide Y and agouti-related protein mRNA levels and body weight in rats. Diabetes. 2001;50:2438-2443.

5. Howard AD, Feighner SD, Cully DF, et al. A receptor in pituitary and hypothalamus that functions in growth hormone release. Science. 1996;273:974-977.

6. Hou Y, An J, Hu XR, et al. Ghrelin inhibits interleukin-8 production induced by hydrogen peroxide in A549 cells via NF-kappaB pathway. Int Immunopharmacol. 2009;9:120-126.

7. Zhang JV, Ren PG, Avsian-Kretchmer O, et al. Obestatin, a peptide encoded by the ghrelin gene, opposes ghrelin's effects on food intake. Science. 2005;310:996-999.
8. Broglio F, Gottero C, Prodam F, et al. Non-acylated ghrelin counteracts the metabolic but not the neuroendocrine response to acylated ghrelin in humans. J Clin Endocrinol Metab. 2004;89:3062-3065.

9. Garcia JM, Garcia-Touza M, Hijazi RA, et al. Active ghrelin levels and active to total ghrelin ratio in cancer-induced cachexia. J Clin Endocrinol Metab. 2005;90:2920-2926.

10. Hosoda H, Kojima M, Matsuo H, et al. Ghrelin and des-acyl ghrelin: two major forms of rat ghrelin peptide in gastrointestinal tissue. Biochem Biophys Res Commun. 2000;279:909-913.

11. Yoshimoto A, Mori K, Sugawara A, et al. Plasma ghrelin and desacyl ghrelin concentrations in renal failure. J Am Soc Nephrol. 2002;13: 2748-2752.

12. Gil-Campos M, Aguilera CM, Canete R, Gil A. Ghrelin: a hormone regulating food intake and energy homeostasis. Br J Nutr. 2006;96: 201-226.

13. Itoh T, Nagaya N, Yoshikawa M, et al. Elevated plasma ghrelin level in underweight patients with chronic obstructive pulmonary disease. Am J Respir Crit Care Med. 2004;170:879-882.

14. Ying BW, Song XB, Fan H, et al. Plasma ghrelin levels and weight loss in Chinese Uygur patients with chronic obstructive pulmonary disease. J Int Med Res. 2008;36:1371-1377.

15. Peng M, Cai BQ, Ma Y, Zu HJ, Sun Q, Song AL. [Circulating leptin and ghrelin in patients with chronic obstructive pulmonary disease]. Zhonghua Jie He He Hu Xi Za Zhi. 2007;30:182-185. Chinese.

16. Luo FM, Liu XJ, Li SQ, Wang ZL, Liu CT, Yuan YM. Circulating ghrelin in patients with chronic obstructive pulmonary disease. Nutrition. 2005;21:793-798.

17. Deveci Y, Deveci F, Ilhan N, Karaca I, Turgut T, Muz MH. [Serum ghrelin, IL-6 and TNF- $\alpha$ levels in patients with chronic obstructive pulmonary disease]. Tuberk Toraks. 2010;58:162-167. Turkish.

18. Nagaya N, Itoh T, Murakami S, et al. Treatment of cachexia with ghrelin in patients with COPD. Chest. 2005;128:1187-1193.

19. Zheng JP, Zhong NS. Normative values of pulmonary function testing in Chinese adults. Chin Med J. 2002;115:50-54.

20. Wilson MM, Thomas DR, Rubenstein LZ, et al. Appetite assessment: simple appetite questionnaire predicts weight loss in communitydwelling adults and nursing home residents. Am J Clin Nutr. 2005;82: 1074-1081.

21. Yang Y, Wang G, Pan X. China Food Composition. Peking, China: Peking University Medical Press; 2002.

22. Briggs DI, Andrews ZB. Metabolic status regulates ghrelin function on energy homeostasis. Neuroendocrinology. 2011;93:48-57.

23. Yang J, Brown MS, Liang G, Grishin NV, Goldstein JL. Identification of the acyltransferase that octanoylates ghrelin, an appetite-stimulating peptide hormone. Cell. 2008;132:387-396.

24. Zhang W, Chai B, Li JY, Wang H, Mulholland MW. Effect of desacyl ghrelin on adiposity and glucose metabolism. Endocrinology. 2008;149:4710-4716.

25. Miki K, Maekura R, Nagaya N, et al. Effects of ghrelin treatment on exercise capacity in underweight COPD patients: a substudy of a multicenter, randomized, double-blind, placebo-controlled trial of ghrelin treatment. BMC Pulm Med. 2013;13:37.
International Journal of COPD

\section{Publish your work in this journal}

The International Journal of COPD is an international, peer-reviewed journal of therapeutics and pharmacology focusing on concise rapid reporting of clinical studies and reviews in COPD. Special focus is given to the pathophysiological processes underlying the disease, intervention programs, patient focused education, and self management protocols.

\section{Dovepress}

This journal is indexed on PubMed Central, MedLine and CAS. The manuscript management system is completely online and includes a very quick and fair peer-review system, which is all easy to use. Visit http://www.dovepress.com/testimonials.php to read real quotes from published authors. 